\title{
AKSESIBILITAS PETANI TERHADAP LEMBAGA KEUANGAN (Studi Kasus : Petani Desa Pakukerto Kecamatan Sukorejo)
}

\author{
Farmers 'Accessibility On Financial Institutions (Case Study: Pakukerto Village Farm- \\ ers, Sukorejo District) \\ M. Idris Sholihin ${ }^{1}$, Idah Lumhatul Fuad ${ }^{1}$ \\ ${ }^{1}$ Program Studi Agribisnis, Fakultas pertanian, Universitas Yudharta Pasuruan \\ E-mail : idris.agribis@gmail.com
}

\begin{abstract}
ABSTRAK
Penelitian ini dilakukan di Desa Pakukerto Kecamatan Sukorejo Kabupaten Pasuruan. Lokasi penelitian ditentukan secara purposiv dengan pertimbangan desa tersebut merupakan desa yang mayoritas penduduknya berprofesi sebagai petani dan luas area pertaniannya melebihi setengah dari luas wilayah pedesaan. Tujuan dari penelitian ini adalah 1). Mengetahui struktur permodalan petani desa Pakukerto, 2). Mengidentifikasi sumber-sumber permodalan yang ada di desa Pakukerto dan 3). Mengetahui aksesibilitas petani Desa Pakukerto terhadap lembaga keuangan. Penentuan sampel atau responden berpedoman pada pakar sampling bahwa untuk mendapatkan data yang representatif, sekurang-kurangnya adalah $10 \%$ dari populasi yang ada. Data dianalisis dengan metode Tabulasi data. Hasil tabulasi data ini dapat menjadi gambaran tentang hasil penelitian karena data-data yang diperoleh dari lapangan sudah tersusun dan terangkum dalam tabel-tabel yang mudah dipahami maknanya. Hasil Penelitian menunjukkan 1) Struktur permodalan petani desa Pakukerto terdiri dari modal sendiri sebanyak 34 responden atau $68 \%$ dan 16 responden atau $32 \%$ menggunakan modal sendiri ditambah modal pinjaman. 2) Sumber-sumber permodalan petani di desa Pakukerto antara Lain : Bank BRI, Bank BPR, Pegadaian, Kelompok Tani. Ada 3 jenis Bank BPR yang ada di kecamatan Sukorejo yaitu BPR Surasari Hutama dan BPR Sukorejo Makmur. 3) Aksesibilitas petani desa pakukerto terhadap lembaga keuangan cukup rendah. Petani desa Pakukerto lebih memilih meminjam ke Kelompok Tani daripada kepada Bank karena prosedur yang terlalu rumit dan adanya pandangan negatif bahwa bunga bank itu menjerat.
\end{abstract}

Kata Kunci : Aksesibilitas, Petani, Lembaga Keuangan

\section{ABSTRACT}

This research was conducted in Pakukerto Village, Sukorejo District, Pasuruan Regency. The research location was determined purposively by considering that the village is a village with a majority of the population working as farmers and the area of agriculture is more than half of the area of the countryside. The purpose of this study is 1). Knowing the capital structure of Pakukerto village farmers, 2). Identify existing capital sources in Pakukerto village and 3). Knowing the accessibility of Pakukerto Village farmers to financial institutions. Determination of samples or respondents guided by sampling experts that in order to obtain representative data, at least $10 \%$ of the existing population. Data were analyzed by the data tabulation method. The results of this tabulation of data can be an illustration of the results of the study because the data obtained from the field have been arranged and summarized in tables that are easy to understand. Research Results show 1) The capital structure of Pakukerto village farmers consists of 34 own capital respondents or $68 \%$ and 16 respondents or $32 \%$ use their own 
capital plus loan capital. 2) The sources of capital of farmers in Pakukerto village include Bank BRI, Bank BPR, Pegadaian, Kelompok Tani. There are 3 types of BPR Banks in Sukorejo sub-district, namely BPR Surasari Hutama and BPR Sukorejo Makmur. 3) Accessibility of Pakukerto village farmers to financial institutions is quite low. Pakukerto village farmers prefer to borrow from the Farmer Group rather than the Bank because the procedure is too complicated and there is a negative view that the bank interest is ensnaring.

Keywords: Accessibility, Farmers, Financial Institutions

\section{PENDAHULUAN}

Indonesia tergolong sebagai negara berpendapatan menengah ke bawah dengan jumlah penduduk miskin cukup banyak walaupun pada tujuh tahun terakhir ini menurut data Badan Pusat Statistik (BPS) mengalami penurunan. Berdasarkan data Badan Pusat Statistik (BPS) pada tahun 2014 jumlah penduduk miskin di Indonesia tercatat 28.28 juta jiwa atau sekitar 11.25 persen. Berdasarkan daerah tempat tinggal, pada periode tahun 20082014, baik jumlah penduduk miskin di daerah perkotaan maupun pedesaan samasama mengalami penurunan. Namun, jumlah dan persentase penduduk miskin di pedesaan masih lebih besar dibandingkan di perkotaan yaitu 17.77 juta orang atau 14.17 persen (BPS, 2014). Hal tersebut menunjukkan bahwa sebagian besar penduduk miskin di Indonesia berada di wilayah pedesaan.

Sebagian besar penduduk miskin yang berada di pedesaan memiliki mata pencaharian sebagai petani yaitu sekitar 63.4 persen. Menurut survei pertanian yang dilakukan oleh BPS tahun 2013, jumlah rumah tangga dengan usaha pertanian terus menurun akibat beberapa hal diantaranya alih jenis profesi dan semakin sempitnya lahan karena alih fungsi lahan untuk pembangunan infrastruktur, pembangunan pabrik dan perumahan.

Menurut Hakim (2008), ada beberapa masalah yang dihadapi sektor pertanian yaitu pertama, sebagian besar petani Indonesia sulit untuk mengadopsi teknologi sederhana untuk meningkatkan hasil produktivitasnya. Teknologi sederhana merupakan pemanfaatan teknologi secara mendasar agar petani tidak terlalu berletih-letih untuk memperoleh hasil sehingga memudahkan manusia. Petani di Indonesia masih banyak yang bercocok tanam menggunakan cara-cara tradisional karena keterbatasan ruang gerak petani terhadap fasilitas yang dimiliki sehingga lambat dalam merespon perubahan yang terjadi di dunia luar. Kedua, petani mengalami keterbatasan pada akses informasi pertanian baik harga produksi, harga faktor produksi maupun pasar dan peluang 
pasar. Petani kurang mengetahui mengenai HPP (Harga Pembelian Pemerintah) dan pembelian akan hasil panen dengan harga rendah bukannya menghasilkan keuntungan melainkan kerugian. Ketiga, sumber daya manusia yang masih rendah. Rendahnya pendidikan di tingkat petani karena pandangan yang berkembang di tengah masyarakat bahwa menjadi petani adalah pilihan terakhir karena tidak memperoleh pekerjaan tempat di sektor lain. Keempat, masalah paling dasar bagi sebagian besar petani Indonesia adalah masalah keterbatasan modal yang dimiliki oleh para petani. Sebagian besar petani mengalami kekurangan modal untuk berusaha dan memenuhi kebutuhan hidupnya, belum adanya asuransi pertanian, masih adanya praktek sistem ijon dan sistem perbankan yang sulit diakses oleh petani.

Berdasarkan empat permasalahan pertanian yang dipaparkan oleh Hakim salah satu permasalahan dalam pertanian adalah masalah keterbatasan atau akses modal. Hal yang sama dikatakan oleh Ashari, ia menyatakan bahwa modal memiliki peran yang sangat strategis dan sampai saat ini sektor pertanian masih menghadapi masalah permodalan (Ashari, 2009).
Menurut Gilarso (1993) dalam Adani (2013), menyampaikan bahwa modal merupakan sarana atau bekal untuk melaksanakan usaha. Secara ekonomi modal adalah barang-barang yang bernilai ekonomi yang digunakan untuk menghasilkan tambahan kekayaan ataupun untuk meningkatkan produksi. Modal dalam usaha tani bersamaan dengan faktor produksi lainnya akan menghasilkan produk. Modal ini semakin berperan dengan berkembangnya usaha tani tersebut.

Ketersediaan modal bagi pelaku usaha pertanian merupakan keharusan. Fungsi modal tidak hanya sebagai salah satu faktor produksi, tetapi juga berperan dalam peningkatan kapasitas petani dalam mengadopsi teknologi seperti benih bermutu, pupuk, alat-alat pertanian, dan teknologi pasca panen.

Kondisi pada masyarakat pedesaan umumnya adalah bahwa sumber daya permodalan untuk usaha tani masih lemah dan cenderung seadanya. Menurut Syukur (2009) dalam Hermawan (2012) hampir 90 persen petani mandiri menggunakan modal sendiri untuk membiayai usaha pertaniannya. Tiap musim tanam tiba, petani mengusahakan modal dari berbagai cara agar dapat menanam, termasuk menggunakan aset pribadi. Sementara 
pendapatan dan aset petani juga digunakan untuk berbagai keperluan keluarganya untuk konsumsi pangan, pakaian, sekolah anak, kesehatan dan biaya sosial.

Pakukerto adalah salah satu desa di kecamatan Sukorejo kabupaten Pasuruan yang kebanyakan penduduknya berprofesi sebagai petani. Luas area persawahan desa Pakukerto sebesar 178 ha, melebihi setengah luas wilayah desa, yakni 260 ha (BPP Sukorejo). Petani di desa Pakukerto masih banyak yang mengalami kesulitan dalam permodalan. Mereka tidak dapat memenuhi kebutuhan modal usaha taninya hanya dengan modal pribadi atau dari hasil pendapatan musim tanam sebelumnya. Hal tersebut dikarenakan tingginya biaya hidup serta mahalnya harga pupuk dan sarana produksi lainnya. Kurangnya permodalan tersebut membuat petani desa Pakukerto perlu untuk mengakses modal dari luar selain modal pribadinya.

Tujuan dari penelitian ini adalah untuk 1) Mengetahui struktur permodalan petani desa Pakukerto kecamatan Sukorejo. 2) Mengidentifikasi sumber-sumber permodalan yang terdapat di desa Pakukerto kecamatan Sukorejo. 3) Mengetahui aksesibilitas petani desa Pakukerto kecamatan Sukorejo.

\section{METODE PENELITIAN}

Lokasi penelitian dilakukan di Desa Pakukerto Kecamatan Sukorejo Kabupaten Pasuruan yang dipilih secara purposive (sengaja). Dasar pemilihan lokasi karena desa Pakukerto wilayahnya mayoritas merupakan lahan pertanian (lebih dari setengah luas total). Responden dalam penelitian ini diambil berdasarkan pedoman dari pakar sampling yang mengatakan bahwa untuk mendapatkan data yang representatif adalah $10 \%$ dari populasi yang ada serta tidak ada aturan yang tegas tentang jumlah sampel yang dipersyaratkan untuk suatu penelitian dari populasi yang tersedia (Singarimbun 1989). Berdasarkan pendapat tersebut maka sampel yang digunakan dalam penelitian ini sebanyak 50 orang, $11 \%$ dari jumlah total petani.

Data yang telah diperoleh kemudian diolah dan diedit terlebih dahulu. Dengan perkataan lain, data atau keterangan yang telah dikumpulkan dalam record book, daftar pertanyaan ataupun pada interview guide perlu dibaca sekali lagi dan diperbaiki, jika di sana sini masih terdapat halhal yang salah atau yang masih meragukan. Kerja memperbaiki kualitas data serta menghilangkan keraguan data dinamakan mengedit data. Beberapa hal perlu diperhatikan dalam mengedit data. 
Setelah diolah dan diberi kode data dianalisis menggunakan metode Tabulasi data. Tabulasi adalah penyusunan data ke dalam bentuk tabel. Tujuan tabulasi adalah agar data bisa mudah disusun, dijumlah, dan mempermudah penataan data untuk disajikan serta dianalisa. Hasil tabulasi data ini dapat menjadi gambaran tentang hasil penelitian karena data-data yang diperoleh dari lapangan sudah tersusun dan terangkum dalam tabel-tabel yang mudah dipahami maknanya (Nazir, 2013).

\section{HASIL DAN PEMBAHASAN}

\section{Gambaran Umum Lokasi Penelitian} Kondisi

Topografi Desa Pakukerto merupakan sebuah desa yang terletak di Kecamatan Sukorejo, Kabupaten Pasuruan, Provinsi Jawa Timur. Terdiri dari lima dusun yaitu dusun Kemiri, Pakunden, Gendol, Janti, dan Mojolengko. Secara geografis desa ini terletak antara $112^{\circ} 33^{\prime}$ - $113^{\circ} 05^{\prime} \mathrm{BT}$ dan $7^{\circ} 32^{\prime}-7^{\circ} 57^{\prime} \mathrm{LS}$. Desa Pakukerto memiliki luas wilayah 260 hektar dengan ketinggian tanah 600-800 meter di atas permukaan laut, dengan karakteristik topografi yang datar dan berbukit sekitar 30 persen. Suhu rata-rata pada musim kemarau berkisar $28^{\circ}$ Celsius sedangkan pada musim penghujan sekitar26-27 Celsius. Desa Pakukerto memiliki curah hujan yang bervariasi anta- ra1387-2459 mm/tahun dengan kelembaban udara 84 persen. Batas-batas desa Pakukerto antara lain sebelah utara berbatasan dengan Desa Glagahsari Kecamatan Sukorejo, sebelah selatan Desa Watu Agung Kecamatan Prigen, sebelah barat berbatasan dengan Desa Gunting Kec. Sukorejo, dan sebelah timur berbatasan dengan Desa Sukorejo Kec. Sukorejo.

\section{Karakteristik Responden}

Jumlah responden pada penelitian ini sebanyak 50 petani yang berada di desa Pakukerto kecamatan Sukorejo. Semua petani responden merupakan anggota kelompok tani. Terdapat lima kelompok tani yang ada di desa Pakukerto. Kelompok tani Watu Gajih, Sumber Sari, Pakunden, Sumber Urip, dan Sumber Barokah. Kelompok tani Watu Gajih terletak di dusun Gendol dengan jumlah anggota 145 petani memiliki luas lahan 51,05 ha. Kelompok tani Sumber Sari terletak di dusun Kemiri dengan jumlah anggota 112 petani memiliki luas lahan 45 ha. Kelompok tani Pakunden terletak di dusun Pakunden dengan jumlah anggota 49 petani memiliki luas lahan 26 ha. Kelompok tani Sumber Urip terletak di dusun Janti dengan jumlah anggota 91 petani memiliki luas lahan 25 ha. Kelompok tani Sumber Barokah terletak di dusun Mo- 
jolengko dengan jumlah anggota 75 petani memiliki luas lahan 30 ha. Rata-rata semua kelompok tani mengusahakan tanaman padi.

Petani responden rata-rata masih berada pada usia produktif. Usia petani responden berkisar antara $30-68$ tahun dengan kriteria jarak umur sebagaimana dilihat pada Tabel 2. Jumlah petani responden terbanyak pada usia antara 40-49 tahun yakni 46 persen. Di antara petani responden tidak ada petani dengan usia di bawah 30 tahun hal ini karena ketertarikan pada sektor pertanian sangat rendah di kalangan orang muda. Petani dengan usia antara 30-39 tahun pun tidak banyak hanya sekitar 26 persen. Tingkat pendidikan petani desa Pakukerto yang digunakan dalam penelitian ini yaitu SD/Sederajat $44 \%$, SMP/Sederajat 46\%, SMA/Sederajat $10 \%$.

\section{Struktur \\ Responden}

Permodalan

Petani

Petani responden di desa Pakukerto kecamatan Sukorejo rata-rata menggunakan modal sendiri dan pinjaman. Modal sendiri yang dimaksud adalah modal yang berasal dari keluarga berupa warisan dan hibah, tabungan hasil panen sebelumnya. Terdapat 68 persen petani responden yang memulai usaha taninya dengan menggunakan modal sendiri kemudian melakukan akses pinjaman saat kekurangan modal di tengahtengah proses produksi. Sisanya 32 persen petani memulai usaha taninya dengan modal sendiri ditambah dengan modal pinjaman. Hal tersebut dikarenakan tingginya biaya hidup keluarga petani sehingga uang hasil panen sebelumnya tidak cukup untuk memulai usaha taninya setelah dikurangi biaya kebutuhan keluarga petani.

Tabel 1 Struktur Modal Petani Responden

\begin{tabular}{llcc}
\hline NO. & $\begin{array}{c}\text { Status } \\
\text { Modal }\end{array}$ & Frekuensi & (\%) \\
\hline 1 & Sendiri & 34 & 68 \\
2 & $\begin{array}{l}\text { Sendiri } \\
\text { dan Pin- }\end{array}$ & 16 & 32 \\
& jaman & & \\
\hline
\end{tabular}

Sumber : Data primer

Sumber Permodalan Tingkat Petani Desa Pakukerto

1. Bank BRI. Bank BRI adalah salah satu bank umum milik pemerintah yang menyediakan layanan kredit bagi masyarakat dengan bunga pinjaman bersaing. Untuk layanan di pedesaan BRI menggunakan sistem kantor cabang pembantu di setiap kecamatan. Petani Desa Pakukerto menggunakan satu kantor cabang dari 
BRI yaitu kantor cabang pembantu di Kecamatan Sukorejo.

\section{Bank Perkreditan Rakyat. BPR} adalah Bank Perkreditan Rakyat (BPR) adalah Bank yang melaksanakan kegiatan usaha secara konvensional atau berdasarkan prinsip syariah, yang dalam kegiatannya tidak memberikan jasa dalam lalu lintas pembayaran. Kegiatan BPR jauh lebih sempit jika dibandingkan dengan kegiatan bank umum karena BPR dilarang menerima simpanan giro, kegiatan valas, dan perasuransian. Terdapat dua Bank BPR di Kecamatan Sukorejo, BPR Makmur dan BPR Surasari Hutama.

Salah satu program pembiayaan yang ditawarkan oleh BPR Surasari Hutama adalah Kredit Musiman. Sasaran dari program ini antara lain : Usaha Pertanian, Usaha Peternakan atau perikanan, Home Industri atau kerajinan, dan Kebutuhan mendesak lainnya. Kelebihan dari program ini adalah bunga yang dibayarkan hanya sebelum jatuh tempo. Setelah jatuh tempo maka nasabah hanya membayar bunga terakhir dan pokok pinjaman.

3. Pegadaian. Pegadaian merupakan lembaga keuangan bukan bank yang memberikan kredit kepada masyarakat dengan cara khusus yaitu hukum gadai. Kantor pegadaian di lokasi penelitian terletak di Ibukota kecama$\tan$.

4. Kelompok tani, Kelompok tani adalah sebuah wadah yang menyatukan petani di suatu wilayah tertentu yang didasari latar belakang yaitu kenyataan petani yang masih lemah dalam mengakses informasi mengenai aspek produksi, aspek kelembagaan dan sumber informasi lainnya. Peran kelompok tani sangat vital pada era pembangunan pertanian saat ini. Terutama dalam pengaliran informasi vertikal antara instansi pemerintahan kepada petani. Kelompok tani yang terdapat dalam lingkup penelitian adalah: 1). Kelompok tani Watu Gajih terletak di dusun Gendol diketuai oleh Bapak Untung W. dengan jumlah anggota 145 petani. 2) Kelompok tani Sumber Sari terletak di dusun Kemiri diketuai oleh Bapak Supardiono dengan jumlah anggota 112 petani. 3) Kelompok tani Pakunden terletak di dusun Pakunden diketuai oleh Bapak Durakhman dengan jumlah anggota 49 petani. 4) Kelompok tani Sumber Urip terletak di dusun Janti diketuai oleh Bapak Jamil dengan jumlah ang- 
gota 91 petani. 5) Kelompok Tani

Sumber Barokah terletak di dusun Mojolengko diketuai oleh Bapak Wahyudi dengan jumlah anggota 75 petani.

\section{Aksesibilitas Petani}

Akses modal petani responden di desa Pakukerto lebih banyak melakukan akses kepada kelompok tani masingmasing. Hal tersebut dikarenakan lebih mudah melakukan peminjaman kepada kelompok tani ketimbang kepada lembaga keuangan berupa bank. Gambaran akses petani responden terhadap lembaga keuangan dapat dilihat pada gambar 4 .

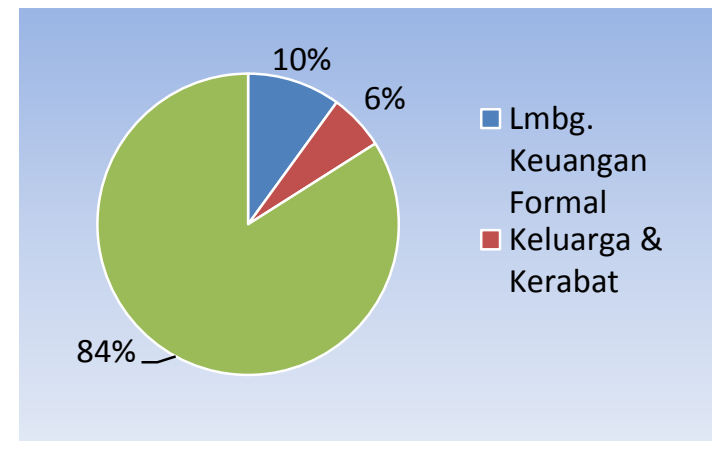

Gambar 1 Akesibilitas petani responden terhadap lembaga keuangan

Berdasarkan bagan di atas sebanyak 42 petani $(84 \%)$ melakukan akses pinjaman kepada kelompok taninya masingmasing. Sisanya 5 petani (10\%) melakukan akses kepada bank dan 3 petani $(6 \%)$ melakukan pinjaman kepada keluarga dan kerabatnya sendiri.

\section{KESIMPULAN DAN SARAN}

Struktur permodalan petani desa Pakukerto rata-rata terdiri dari modal sendiri dan modal pinjaman. Sumber-sumber permodalan yang terdapat di Desa Pakukerto Kecamatan Sukorejo antara lain Bank BRI Unit Desa, Bank BPR Surasari Hutama, Bank BPR Sukorejo Makmur, Pegadaian, Kelompok Tani.

Lembaga keuangan yang paling banyak diakses petani berturut-turut adalah Kelompok Tani delapan puluh empat persen $(84 \%)$, sepuluh persen (10\%) akses kepada lembaga keuangan Bank dan enam persen $(6 \%)$ melakukan akses pinjaman kepada kerabat.

\section{DAFTAR PUSTAKA}

Adani, Amalia. (2013). Teori Permodalan ISLAM. [Makalah]. Universitas Islam Negeri Syarif Online tersedia http://amaliaadani.wordpress.com. Diakses pada tanggal 18 Juli 2017

Ashari. (2009). Peran Perbankan Nasional dalam Pembiayaan Sektor Pertanian Di Indonesia. Pusat Analisis Sosial Ekonomi dan Kebijakan Pertanian. Volume 27 No 1. 13-27. Bogor (ID).

Badan Pusat Statistik (ID). (2014). Berita Resmi Statistik BPS No.83/11/Th.XVII,5 November 2014 [Internet]. [diunduh Juli 2017].Tersedia pada: 
https://www.bps.go.id/brs_file/No.8

311Th.XVII5November2014.pdf.

Hakim, L. (2008). Kelembagaan dan Kemiskinan Indonesia [Internet]. [diunduh 22 April 2017]. Tersedia pada:

http:www.google.com//kelembagaa $\mathrm{n} / / \mathrm{html}$

Hermawan, H., Andruanyta, H. (2012). Lembaga Keuangan Mikro Agribisnis: Terobosan Penguatan Kelembagaan dan Pembiayaan Pertanian di Perdesaan. Jurnal Analisis Kebijakan Pertanian. Volume 10 No. 2. Bogor (ID).

Nazir, Moh. (2013). Metode Penelitian. Ghalia Indonesia : Bogor 